\title{
An experimental feasibility study of using diesel exhaust for space heating in Alaskan Villages
}

\author{
P. Raghupatruni, C.-S. Lin, D. Witmer, E. Bargar, J. Schmid, \\ T. Johnson \& V. Avadhanula \\ Department of Mechanical Engineering, University of Alaska Fairbanks, \\ USA
}

\begin{abstract}
In rural Alaska, there are nearly 180 villages consuming about 374,000 $\mathrm{MWh}$ of electrical energy annually from individual diesel generators. A similar amount of fuel energy is dissipated into the atmosphere from diesel exhaust. Due to the isolation and small populations of the villages, the costs of fuels, components, and maintenance are extremely high and one of the policies in management is to minimize the possibilities of power outrage and the frequency of maintenance. Also due to the potential of corrosion and soot accumulation in exhaust heat recovery systems, exhaust heat recovery has long been avoided. Recently, the surge in fuel prices, the new regulation requiring ultra low sulfur diesel, and the desire to reduce green house gas has led to exhaust heat recovery being reconsidered for improving the energy efficiency of rural Alaskan diesel power plants.

This report discusses the selection of different exhaust heat recovery applications to the villages, the design of an experimental system that simulates different space heating methods used in villages, system fabrication, instrumentation, system performance, feasibility and economic analysis. Performance presented includes the effect of the heat recovery system on engine performance, heat recovery effectiveness, measured soot accumulation and the effect of fouling on heat recovery effectiveness, and the estimated maintenance requirement.
\end{abstract}

Keywords: exhaust heat recovery, experimental simulation, space heating, soot accumulation, feasibility, payback time. 


\section{Introduction}

Rural Alaskan villages consume about 374,000 MWh of electric energy from individual diesel generators [1]. The single largest amount of unused heat from engines is exhaust heat, which contains about $30 \%$ of the fuel energy. Work which studies the selection of the most appropriate engine heat recovery method is needed as part of the village economic development. Several heat recovery applications have the potential to be economic and feasible for Alaskan villages, such as desalination [2], ice making [3], direct thermal electric conversion [4], heat to power conversion [5-7], and space and water heating [8]. Desalination did not appear to be locally useful due to the mineral contents of ground water for most of the Alaskan villages [9], which were well within acceptable ranges. Direct thermal to electricity conversion was not selected due to its low conversion efficiency. Ice making has been demonstrated in one of the villages, but unless there is a large commercial user for ice, the cost was not justified.

Both heat to power conversion and space and water heating were expected to have reasonable recovery efficiencies. Heat to power conversion can easily transform the heat into a convenient form of energy. Based on some current reports $[5-7,10]$, the expected improvement in fuel efficiency of different heat to power conversion applications were about 10\%. However, Most of the development for medium size diesel engines, which were the majority of the engines used in Alaskan villages, is still in the research and prototyping stages. Based on the efficiencies of the readily available components, an exhaust heat recovery system for space and water heating could be easily fabricated to deliver $50 \%$ or more of the exhaust heat energy (i.e. $15 \%$ or more of fuel energy) [11].

This project studies the feasibility and economic effect of applying exhaust heat recovery for space heating to Alaskan village diesel generators. Heat recovery for thermal to power would be the subject of the next study. Space heating, which included public space heating using baseboard and floor radiant systems, were also proposed by the Alaska energy authority as candidates for future rural Alaska cogeneration development [8]. The following sections describe details of the diesel generator and the heat recovery system used for this study along with system instrumentation, experimental results, and the final conclusion.

\section{Test bed}

This section discusses the test bed and the details of the heat recovery system.

\subsection{The diesel generator system}

This experiment was conducted using a DD50 diesel-generator set, one of the typical diesel generators used in villages. The generator was connected to a 250 $\mathrm{kW}$ external resistive/reactive load bank for engine load control and simulation. Load bank was interfaced with LABVIEW IV system for load control signals. The diesel generator set and data acquisition system were placed inside an ISO 
container while the load bank sitting outside of the ISO container. Details can be found in [12]. Property of the diesel engine is listed in Table 1.

\subsection{Exhaust heat recovery system}

The exhaust heat recovery system was designed according to the following requirements:

Apply existing technology.

Optimize overall efficiency for varying engine load (In general, the load of a village generator may range from $25 \%$ to $100 \%$ of rated load).

Minimize corrosion to exhaust system.

Meet back pressure requirement (13.8 $\mathrm{kPa}$ or $2 \mathrm{psi})$.

Meet dimension constraints (very limited space).

Be able to emulate different space heating applications of Alaskan villages.

Be able to measure system and component performance.

Be easy to maintain and do not increase maintenance frequency.

Work under a wide range of ambient temperatures $\left(-40^{\circ} \mathrm{C}\right.$ to $\left.33^{\circ} \mathrm{C}\right)$.

Be reliable.

Table 1: Diesel engine properties.

\begin{tabular}{|l|l|}
\hline Number of cylinder: 4 & Number of Stroke: 4 \\
\hline Bore x Stroke: $130 \mathrm{~mm}$ x $160 \mathrm{~mm}$ & Fuel Injection: Electronic unit injector \\
\hline Aspiration: Turbocharged & Displacement: $8.5 \mathrm{~L}$ \\
\hline Rated Power: $125 \mathrm{~kW}$ & Rated Speed: $1200 \mathrm{rpm}$ \\
\hline Exhaust Gas Recirculation: None & Exhaust After treatment: None \\
\hline
\end{tabular}

Based on the requirements, an experimental heat recovery system was designed and installed. The system had three major sections: the heat source section (Figure 1A), the heat sink or load section (Figure 1B), and the pipe and control section (Figure 1C). The source section had a heat exchanger and auxiliary components to capture heat from engine exhaust. The heat sink section had a unit heater and auxiliary components to simulate the village load and was designed to work in such a way that the source or load could be controlled at specific temperatures at different engine loads. The pipe and control section was used to transport working fluid between the heat source and the heat sink and able to control the flow rate and pressure distributions of the system.

Based on the computation results $[13,14]$ and the availability of commercial products for high temperature exhaust, a shell and tube type of heat exchanger was selected. The exhaust gas passed through the shell side and the liquid coolant through the core side. For maintenance purposes, the core was removable for cleaning when necessary. In order to have the heat exchanger be able to absorb the most amount of heat, the designed size of the heat exchanger was based on the exhaust condition at full engine load. For partial engine load 
conditions, the heat recovery system was designed with parameters adjustable to make the coolant inlet or outlet temperature match the requirements of different heating applications. The heat exchanger coolant inlet side temperatures used for design (Table 2) were selected based on the feed water temperature of $65^{\circ} \mathrm{C}$ typical of boilers used for baseboard heating in rural Alaska [8]. So a temperature of $77^{\circ} \mathrm{C}$ would be adequate for pre-heating the boiler feed water. The inlet gas temperature used for design was the full load exhaust temperature and the outlet gas temperature was based on the acid condensation formation temperatures $[14,15]$ of the exhaust and also based on the trade off between the cost and the amount of heat to be recovered. Some of the details of the selected heat exchanger are shown in Table 3.

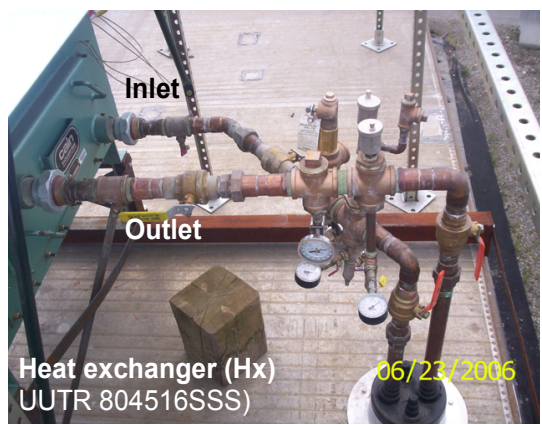

(a)

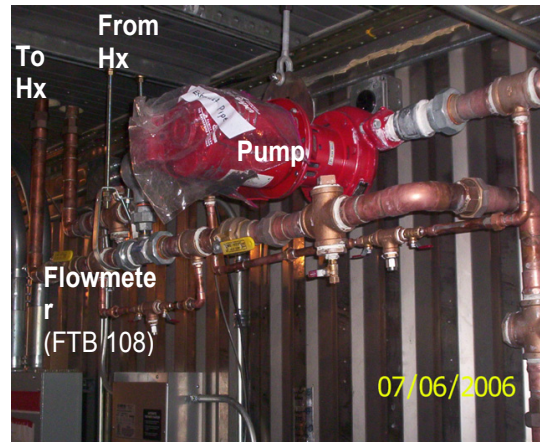

(c-1)

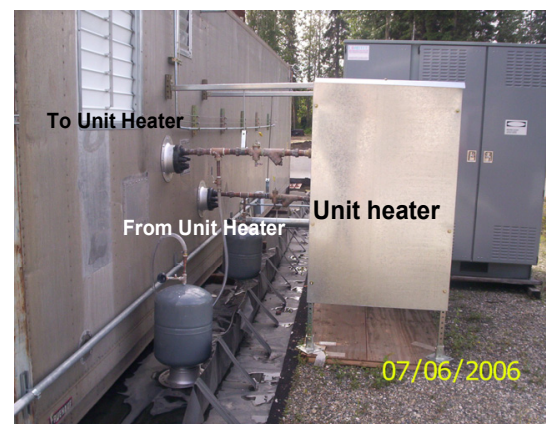

(b)

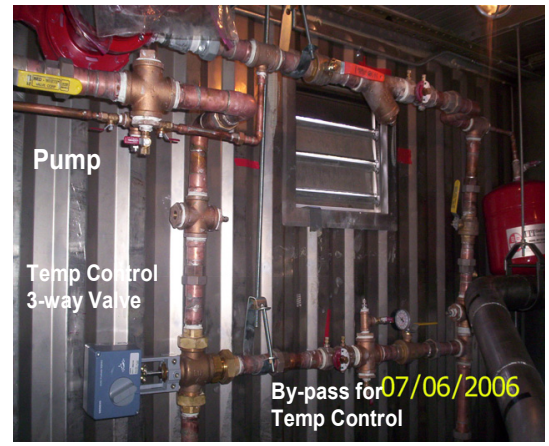

(c-2)

Figure 1: The heat recovery system. (a): Heat exchanger section (top of container). (b): Unit hater section (outside of container). (c-1): Pipe and control elements (south half). (c-2): Pipe and control elements (north half).

The heat dissipating capacity of the selected unit heater was above the expected maximum amount of heat absorption rate of the heat exchanger with a safety margin. A bypass loop and a 3 way temperature control valve were selected for the control of the outlet temperature of the load section by appropriately distributing the total flow between the bypass loop and the unit heater. 
The pipe and control section included the pipes between the heat exchanger section and the load section, a pump and other miscellaneous components (i.e. ball valves, expansion tank, circuit setters, snubbers, dielectric unions, fittings, insulation material, etc.) were designed to control the system operation and to meet the needs for maintenance, instrumentation, corrosion prevention, etc. The pump was selected based on the design flow rate and calculated total pressure drop [16] of the system with the effects of all the expected system components.

\section{Instrumentation and test procedure}

\subsection{Instrumentation}

The purpose of instrumentation was for system operation monitoring and system data collection. A National Instrument data acquisition system (DAQ) was used to document the experimental readings. Temperature data were used to estimate the system and components efficiencies, possibility of condensation formation in exhaust pipe and heat exchanger, and effect of fouling on system performance. Pressure data were used to monitor and evaluate the condition of the flow path and the functions of the components. The locations of the temperature sensors and the coolant flow meter along the pipe system are shown in Figure 2. There were also 5 thermal couples installed at the heat exchanger exhaust outlet to measure the instantaneous average temperatures of exhaust and 10 thermal couples installed on the outside walls of the heat exchanger core tubes to monitor the temperature drop across the heat exchanger. The exhaust temperature at the inlet of the heat exchanger was obtained from a sensor came with the original engine generator set.

Table 2: $\quad$ Inlet/outlet temperatures of heat exchanger.

\begin{tabular}{|c|c|c|}
\hline & Inlet temperature & Outlet temperature \\
\hline Exhaust & $540^{\circ} \mathbf{C}$ & $177^{\circ} \mathbf{C}$ \\
\hline Coolant & $77^{\circ} \mathbf{C}$ & $87^{\circ} \mathbf{C}$ \\
\hline
\end{tabular}

Table 3: $\quad$ Heat exchanger parameters.

\begin{tabular}{|c|c|}
\hline Shell side & Gas \\
\hline Tube side & Liquid \\
\hline Gas pressure drop & 0.31 PSI \\
\hline Maintenance & Removable core \\
\hline Heat transfer area & $87 \mathrm{ft}^{2}$ \\
\hline Size & 51 "x28"x28" \\
\hline Weight & $725 \mathrm{lbs}$ \\
\hline Material of construction & Tube- SS fin tube \\
& Shell- SS inner wall \\
\hline Insulation & Integrated insulation \\
\hline
\end{tabular}

In addition to the measurements mentioned above, engine inlet air flow rate and property (i.e. temperature, pressure, humidity) and engine fuel consumption rate were also measured and used for exhaust flow rate calculations. Details can 
be found in $[12,17]$. Sensors for mass flow rates of fuel consumption and coolant flow were calibrated gravimetrically.

\subsection{Test procedure}

The heat recovery system was operated and monitored for nearly 350 hours after installation. In order to observe the worst case scenario, the fuel used for testing was the conventional diesel fuel and the engine was not equipped with any of the after-treatment devices. The system was operated under generator rated load conditions $(125 \mathrm{KW})$ for most of the time. The system was also operated under different engine loads $(25 \%, 50 \%$, and $75 \%)$ for performance testing. For each load, the heat recovery system was tested for three different types of space heating applications defined by the coolant outlet temperatures of the heat exchanger [8].

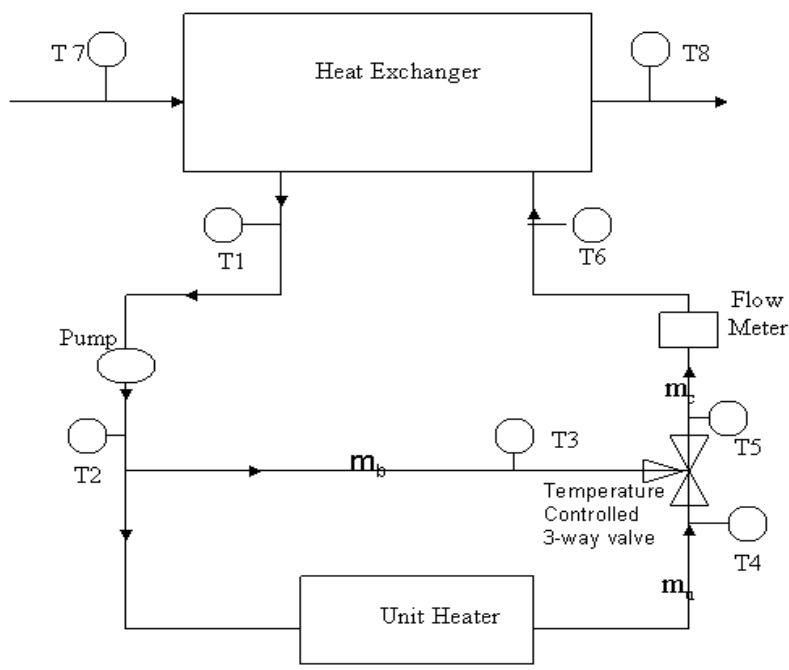

Figure 2: Locations of temperature sensors and flow meter.

During the first 150 hours of test conducted in summer 2006, water was used as coolant to investigate the defects in installation and calibrations and the effect of adding the heat recovery system on general engine performance. At the $150^{\text {th }}$ hour, the coolant was changed from water to $40 \%$ propylene and $60 \%$ water mix to avoid freezing and the flow meter was recalibrated. The next 100 hours test, conducted in fall 2006 was to investigate the measurement reliability and performance consistency. After the $250^{\text {th }}$ hour, one of the thermocouples was recalibrated and the time constant of the temperature control valve was adjusted to limit the fluctuation in the temperature readings.

Data collected during the last 100 hours test conducted in the winter of early 2007 was used for most of the analysis because the data were considered more accurate. In this report, the analysis results were mostly based on the data 
collected between the $250^{\text {th }}$ hour and $300^{\text {th }}$ hour. During this period, the engine was operated under full load and data was used to investigate the general system performance, feasibility, and payback time. Between the $300^{\text {th }}$ hour and $350^{\text {th }}$ hour, the engine was operated under 4 different engine loads (i.e. $25 \%, 50 \%$, $75 \%$, and $100 \%$ of rated load) and data was used to investigate the effect of the load on the performance of the heat recovery system.

\section{Results and discussion}

This section discusses the measured data and analysis results.

\subsection{System performance}

Based on the first 100 hours test data, no engine performance was found significantly altered. Some of the data is listed in Table 4. Performance data of the exhaust heat recovery system obtained during the period between the $250^{\text {th }}$ hour and $300^{\text {th }}$ hour is given in Table 5 .

Table 4: $\quad$ Engine performance data before installation of the heat recovery system and at the $50^{\text {th }}$ hour and $100^{\text {th }}$ hour.

\begin{tabular}{|l|c|c|c|}
\hline Engine hours & $\begin{array}{l}\text { Exhaust T } \\
\text { (Degree C) }\end{array}$ & $\begin{array}{l}\text { Turbocharger } \\
\text { T (Degree C) }\end{array}$ & $\begin{array}{l}\text { Fuel consumption } \\
(\mathrm{L} / \mathrm{hr} \text {.) }\end{array}$ \\
\hline Before the installation & 542 & 122 & 34 \\
\hline $50^{\text {th }}$ hour & 540 & 142 & 34 \\
\hline $100^{\text {th }}$ hour & 533 & 140 & 34 \\
\hline
\end{tabular}

Table 5: $\quad$ Performance data of the exhaust heat recovery system during the period between $250-\mathrm{hr}$ and $300-\mathrm{hr}$.

\begin{tabular}{|l|r|r|r|r|r|}
\hline Measured Data & $10 \mathrm{Hr}$ & $20 \mathrm{Hr}$ & $30 \mathrm{Hr}$ & $40 \mathrm{Hr}$ & $50 \mathrm{Hr}$ \\
\hline Exhaust Flow (Kg/s) & 0.25 & 0.24 & 0.24 & 0.24 & 0.25 \\
\hline Exchanger exh inlet T (C) & 511.5 & 503.0 & 487.0 & 495.9 & 517.1 \\
\hline Exchanger exh outlet T C) & 215.6 & 220.6 & 207.9 & 214.5 & 226.6 \\
\hline Coolant flow rate (Kg/s) & 1.45 & 1.48 & 1.45 & 1.45 & 1.43 \\
\hline Exchanger coolant inlet T (C) & 76.89 & 76.53 & 77.07 & 77.03 & 75.82 \\
\hline Exchanger coolant outlet T (C) & 88.45 & 87.05 & 87.74 & 87.53 & 87.34 \\
\hline Before bypass (load) T (C) & 88.02 & 86.79 & 87.36 & 87.00 & 86.83 \\
\hline After 3way valve (load) T (C) & 76.91 & 76.94 & 77.08 & 76.75 & 75.52 \\
\hline Flow rate in bypass (Kg/s) & 1.00 & 1.13 & 1.02 & 1.00 & 0.83 \\
\hline Flow across unit heater (Kg/s) & 0.45 & 0.35 & 0.43 & 0.45 & 0.60 \\
\hline Outside ambient T (C) & -23.0 & -30.0 & -18.0 & -15.0 & -7.0 \\
\hline
\end{tabular}

The performance data showed that the ambient temperature has a noticeable effect on the flow distribution of the system between the bypass and the unit heater (Figure 3) as expected. It also shows that the heat dissipated from the unit 
heater was higher for higher ambient temperatures. This can be explained as, at higher ambient temperatures, the pipeline dissipates less heat that needed to be compensated by increasing heat loss through the unit heater to maintain the inlet temperature of the heat exchanger. The energy balance was checked between the heat absorbed from the exhaust side and heat dissipated from the load side. Figure 4 shows that the heat absorbed by coolant equals the sum of heat dissipated with an error of less than $3 \%$.

Figure 4 also shows the heat release rate from the exhaust and the heat absorption rate of the coolant. The heat release rate of the exhaust across the heat exchanger was based on the enthalpy change of exhaust components after combustion. The heat absorption rate was evaluated using the coolant mass flow rate, specific heat and the temperature difference between the heat exchanger inlet and outlet flow. The amount of heat absorbed by the coolant followed the same trend as the heat released from exhaust across the heat exchanger.

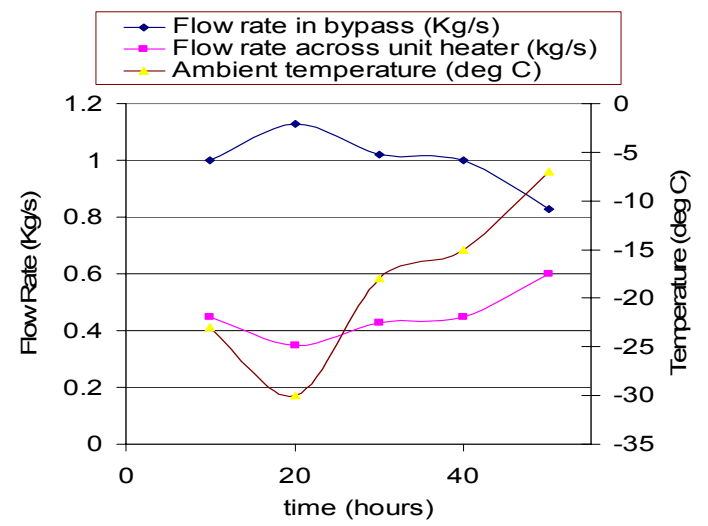

Figure 3: $\quad$ Flow distributions between the bypass and the unit heater.

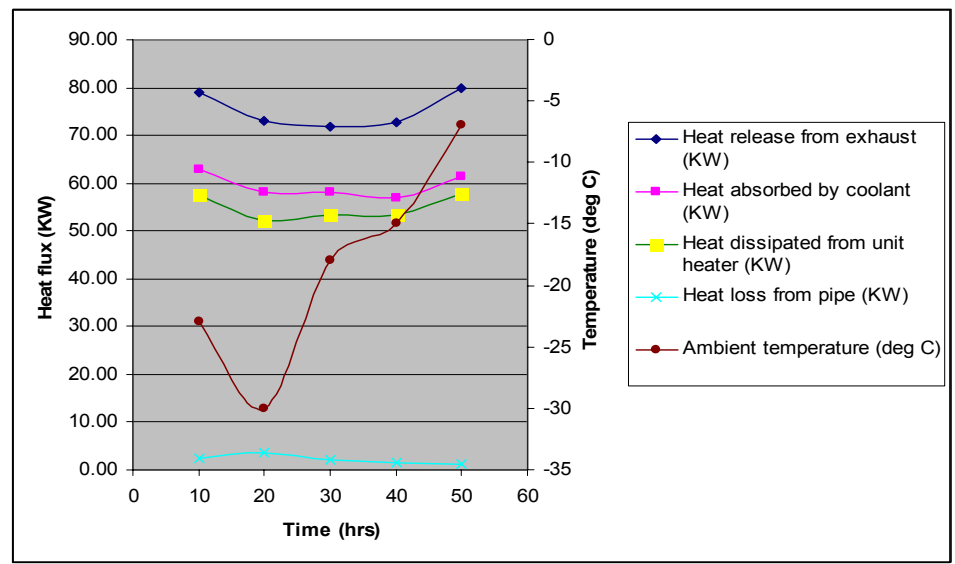

Figure 4: Heat absorption and dissipation with respect to the ambient temperature. 


\subsection{Soot accumulation and corrosion}

Both soot accumulation and corrosion were considered critical parameters, as they were known to have negative effect on the performance and maintenance of heat recovery systems. This section presents the results obtained from the observation of soot accumulation and corrosion inside the heat exchanger after 350 hours of operation of the exhaust heat recovery system.

Over a span of 350 hours of run time, the total soot produced by the exhaust gas was expected to be 3000 to 6000 grams as much of the PM passes through the heat exchanger. After the experiments, the heat exchanger was dismantled and cleaned and about 150 grams of soot was found to be accumulated. Figure 6 shows the soot accumulated on an arbitrarily selected finned tube. This result matches a general believe that soot accumulated on finned tubes may approach to its asymptote within a relatively short period of time [18, 19]. The heat exchanger overall heat transfer coefficients estimated using the experimental data are shown in Figure 7. The values of the overall heat transfer coefficients, which may be affected by the transient values of exhaust gas flow rate and ambient temperatures and fouling resistance, show no monotonic decreasing trend. The trend doesn't conflict with the general believe. Also based on experimental data, estimated average fouling resistance and gas side heat transfer resistance were 0.0105 and $0.0226 \mathrm{~m}^{2}{ }^{\circ} \mathrm{K} / \mathrm{W}$ respectively. With this small amount of soot accumulated and the simple process needed for cleaning, the heat exchanger needs maintenance not more than twice a year, which is considered no impact to the maintenance frequency of the diesel generator set.

When the heat exchanger was dismantled, the corrosion effect of exhaust gas on the heat exchanger was also investigated by examining the surface for the existence of corrosion spots on both tube and shell sides. No trace of any such corrosion was observed. The reason seems to be that the exhaust temperature was always kept above the acid dew point. This resulted in an absence of condensate in the heat exchanger throughout the run time. The material, SS $316 \mathrm{~L}$, used to construct the inside of the heat exchanger may also have the contribution.

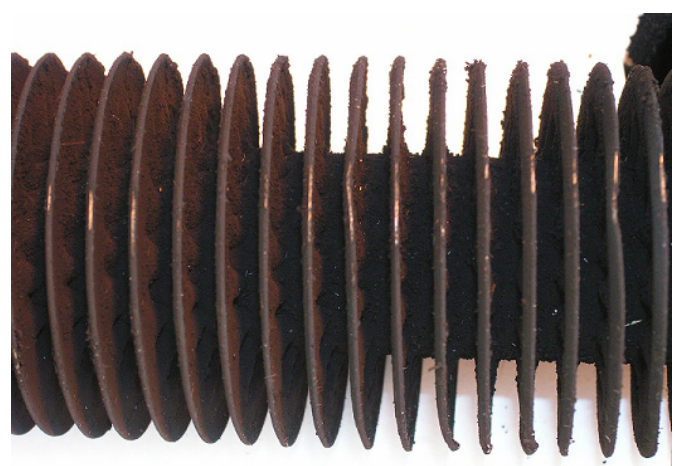

Figure 5: Soot accumulations on the fins. 


\subsection{Economic analysis}

The economic analysis was done based on the present heat recovery system and diesel generator used for this experiment and an assumption of $100 \%$ use of the recovered heat. The heat recovery rate was taken to be $60 \mathrm{~kW}$ at rated load with 8 hours per day. Other parameters used in this calculation include:

Initial cost of the recovery system $=\$ 30,000$.

Installation cost $=\$ 5,000(\$ 75 / \mathrm{hr} \times 8$ hrs /day $\times 10$ days $)$.

Airfare, lodging, meals $=\$ 1,950$ ( $\$ 600 /$ round trip $+\$ 90 /$ day x 15 days $)$.

Total capital cost $=\$ 37,950$.

Heat recovery per hour $=204,728$ BTU.

Heating value for conventional fuel $=130,000 \mathrm{BTU} / \mathrm{gal}$.

The heat recovery system maintenance cost was based on one day of labor $(\$ 75 / \mathrm{hr})$ and a round trip flight ticket $(\$ 600)$, which comes to $\$ 1,200$ for 6 months of engine operation. The maintenance costs also include additional money $(\$ 300)$ every year for supplies.

Pay back time was calculated (Figure 8) with respect to different fuel prices based on two different interest rates and an engine operation of 8 hours per day. The payback time for a $100 \%$ use of recovered heat would be less than 3 years based on the fuel price of $\$ 3.50 /$ gallon, $10 \%$ interest rate, and an engine operation of 8 hours per day.

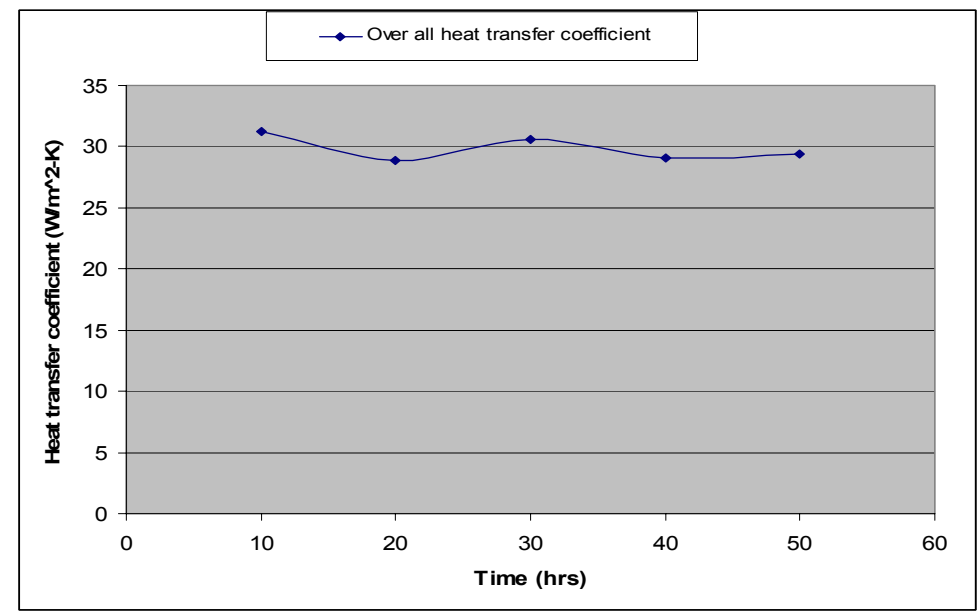

Figure 6: Overall heat transfer coefficient versus time.

\section{Conclusions}

An experimental work was conducted to check the feasibility and economic effect of applying exhaust heat recovery to a diesel engine generator system. The collected data and analysis results lead to the following conclusions:

1. The performance of our exhaust heat exchanger was reliable and consistent. 
2. For the $125 \mathrm{~kW}$ diesel generator used in this experiment, the rate of heat recovered from the exhaust was about $60 \mathrm{~kW}$.

3. No effects were observed on the engine performance and maintenance frequency due to the heat recovery system.

4. According to the soot accumulation data obtained from this experiment, the estimated time for heat exchanger maintenance is less than two days per year.

5. Corrosion was not observed to be a problem in the laboratory test of 350 hours.

6. Based on experimental data obtained from this experiment, the estimated payback time for a $100 \%$ use of recovered heat would be less than 3 years for a fuel price of $\$ 3.5$ per gallon and an engine operation of 8 hours per day. For $80 \%$ use of the recovered heat, the payback time would be 4 years.

7. Operation cost is largely case dependent. Influential parameters would include diesel fuel cost, the application of the recovered heat, location of the power plant, etc.

8. Performance and economic outcomes will be different from one case to another. For example the existing infrastructure of the community water heating system may largely affect the capital cost due to the high cost of the outdoor arctic tubing and installation requirement. However, analysis is recommended before the installation of an exhaust heat recovery system to a village generator set.

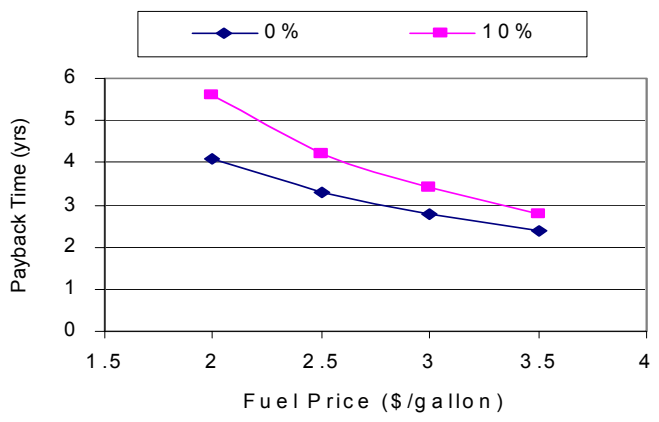

Figure 7: Payback time with respect to fuel price and interest rate (engine with an operation of 8 hours per day).

\section{Acknowledgement}

The authors are grateful to US-DOE-NETL for supporting this project (contract number DE-FC26-01NT41248). Thanks are also due to ICRC Corporation for providing the diesel generator set used for the experiment and AVEC Corporation for providing the village diesel generator operation data used for the load pattern analysis. 


\section{References}

[1] Alaska Electric Power Statistics, Institute of Social and Economic Research, University of Alaska Anchorage, Prepared for Alaska Energy Authority, November 2003.

[2] H. T. El-Dessouky, "Fundamentals of Salt Water Desalination," Elsevier Science Ltd, 2002.

[3] J. Dakoozian, "Absorption chilling and ice production," 2004 Alaska Rural energy conference, Session 2B, 2004.

[4] H. Schock, et al., "Thermoelectric conversion of waste heat to electricity in an IC engine powered vehicle," 2007 Diesel Engine-Efficiency and Emissions Research Conference, Aug. 2007.

[5] C. T. Vuk, "Electric turbo compounding technology update," 2007 Diesel Engine-Efficiency and Emissions Research Conference, Aug. 2007.

[6] C. R. Nelson, "Cumins waste heat recovery," 2007 Diesel EngineEfficiency and Emissions Research Conference, Aug. 2007.

[7] D. J. Patterson and R. W. Kruiswyk, "An engine system approach to exhaust waste heat recovery," 2007 Diesel Engine-Efficiency and Emissions Research Conference, Aug. 2007.

[8] Rural Alaska Energy Plan- Cogeneration Chapter, MAFA, Prepared for Alaska Energy Authority, Dec. 2002.

[9] Ground water data for Alaska, 2003, http://waterdata.usgs.fov/ak/nwis/gw.

[10] R. Chellini, "Diesel \& Gas Turbine Worldwide," Sept. 2007.

[11] S. Stassel, "An approach to heat recovery in rural Alaska," Alaska Rural Energy Conference, 2004.

[12] A. Telang, "Testing of syntroleum fuels in diesel power plants suitable for Alaska," M.S. thesis, Dept. Mech. Eng., Univ. of Alaska Fairbanks, Fairbanks, Alaska, 2005.

[13] P. R. Raghupatruni, "Performance Analysis of capture of heat energy from diesel engine exhaust," M.S. thesis, Dept. Mech. Eng., Univ. of Alaska Fairbanks, Fairbanks, Alaska, 2007.

[14] R. K. Shah, Fundamental of Heat Exchanger Design, John Wiley \& Sons, 2003.

[15] V. Ganapathy, Minimizing Acid Condensation Concerns, http://vganapathy.tripod.com/corros.html.

[16] ASHRAE Handbook-Fundamentals, ASHRAE, 2005.

[17] S. Kanthikiran, "Properties and performance evaluation of syntroleum Synthetic diesel fuels," M.S. thesis, Dept. Mech. Eng., Univ. of Alaska Fairbanks, Fairbanks, Alaska, 2005.

[18] J. Grillot and G. Icart, "Fouling of a cylindrical probe and a finned tube bundle in a diesel exhaust environment," Experimental Thermal and Fluid Science, Vol. 14, Issue 4, 1988, pp 442-454.

[19] W. J. Marner, "Progress in gas-side fouling of heat-transfer surfaces," Applied Mechanics Reviews, Vol. 43, No. 3, March 1990, pp 35-66.

[20] B. Adrian, Heat Transfer, John Wiley, 1993. 